\title{
CONSTRUÇÃo DE CÉLULA ELETROQUÍMICA PARA OBSERVAÇÃo DE AMOSTRAS IN SITU EM ESTEREOMICROSCÓPIO
}

\author{
Mônica Alessandra Silva Alencar *, Assis Vicente Benedetti, Cecílio Sadao Fugivara e Younès Messaddeq \\ Instituto de Química, Universidade Estadual Paulista, CP 355, 14801-970 Araraquara-SP, Brasil
}

Recebido em 4/9/09; aceito em 1/2/10; publicado na web em 18/6/10

\begin{abstract}
CONSTRUCTION OF AN ELECTROCHEMICAL CELL TO VISUALIZE SAMPLES in situ IN STEREOMICROSCOPE. The electrochemical study of glass like tungsten oxide derivatives requires the construction of special electrodes due to the fact that these glasses are not conductive. Electrodes modified with $\mathrm{WO}_{3}$ change their color when submitted to some potential perturbation. The color change of the electrochromic materials was observed in situ by coupling an electrochemical cell to a stereomicroscope. The constructed cell is versatile and may represent a great contribution to the electrochemical studies of materials, especially in the systems where it is interest to observe the working electrode surface during the electrochemical experiment.
\end{abstract}

Keywords: electrochemical cell; stereomicroscope; electrochromism.

\section{INTRODUÇÃO}

A eletroquímica possui uma série de técnicas bem consolidadas, difundidas e eficientes para fornecer as mais variadas informações sobre termodinâmica de processos redox, cinética de reações de transferência de carga e de reações químicas acopladas, processos de adsorção e dessorção, reações em estado sólido, entre outras, sobre as reações eletroquímicas. Porém, o desenvolvimento de novos dispositivos, que quando associados a essas técnicas são capazes de fornecer informações mais detalhadas do sistema em estudo, é sempre de grande interesse e, muitas vezes, representa um desafio.

Os estudos eletroquímicos são de grande importância na investigação dos materiais eletrocrômicos, que são materiais opticamente ativos que despertam enorme interesse devido às suas potenciais aplicações.

Dentre os diferentes efeitos cromógenos, o eletrocromismo (um efeito do estado sólido) e o eletroquimicromismo (um efeito eletroquímico) são propriedades características de alguns materiais ou sistemas, que apresentam mudança de cor (absorção e/ou reflexão espectral) reversivelmente, em resposta a uma perturbação elétrica externa, permitindo uma série de aplicações. ${ }^{1-9}$ Para o estudo desses materiais podem ser usadas diversas técnicas, como voltametria cíclica, ${ }^{10-14}$ espectroscopia de impedância eletroquímica ${ }^{15}$ e até técnicas eletroquímicas mais recentes, como ruído eletroquímico. ${ }^{16}$ Embora esse fenômeno eletrocrômico tenha sido extensivamente estudado por diferentes técnicas, a mudança de coloração característica desses materiais, dentro do conhecimento dos autores, não foi anteriormente observada in situ.

A contribuição deste trabalho consiste no desenvolvimento de uma célula eletroquímica acoplada a um estereomicroscópio que permite fotografar a superfície do eletrodo de trabalho in situ, simultaneamente à aplicação de uma perturbação elétrica (potencial ou corrente) tal como, por exemplo, uma varredura de potenciais.

Apesar de muito valiosa para observação de mudança de cor, a utilização dessa célula não está restrita aos estudos de materiais cromógenos, podendo também ser utilizada em estudos de corrosão, observação de defeitos em revestimentos, como micropites, delaminação, entre outros, e uma série de outras possíveis aplicações em diferentes estudos eletroquímicos.

\footnotetext{
*e-mail: monica@iq.unesp.br
}

\section{PARTE EXPERIMENTAL}

\section{Descrição da célula eletroquímica acoplada ao estereomicroscópio}

A Figura 1 mostra a célula eletroquímica construída em PTFE, sendo constituída por duas partes: superior e inferior. A parte superior tem $15 \mathrm{~mm}$ de altura, $50 \mathrm{~mm}$ de diâmetro interno, $70 \mathrm{~mm}$ de diâmetro externo e um orifício central com $10 \mathrm{~mm}$ de diâmetro. $\mathrm{Na}$ parte inferior desse orifício há uma reentrância para encaixe do anel de vedação de silicone. A capacidade da célula é de até $20 \mathrm{~mL}$ (Figura 1a (A)). A parte inferior da célula (Figura 1a (B)) tem $70 \mathrm{~mm}$ de diâmetro externo com um tarugo de aço inoxidável embutido no centro da peça. Esse tarugo serve de contato elétrico para o eletrodo de trabalho. Essas duas partes se encaixam entre si e são fixadas uma a outra por três parafusos de $3 \mathrm{~mm}$ de diâmetro (Figura 1a (C)).

$\mathrm{Na}$ parte superior da célula foram inseridas duas espirais unidas em curto-circuito e feitas com fio de platina de $0,5 \mathrm{~mm}$ de diâmetro por $50 \mathrm{~mm}$ de comprimento, constituindo-se no eletrodo auxiliar. Como referência foi utilizado um microeletrodo de $\mathrm{Ag} / \mathrm{AgCl} / \mathrm{KCl} 3 \mathrm{~mol} \mathrm{~L}-1$ inserido num tubo de borossilicato de $3 \mathrm{~mm}$ de diâmetro por $25 \mathrm{~mm}$ de comprimento. $\mathrm{Na}$ extremidade inferior foi soldado um fio de $\mathrm{Pt}$ de $0,5 \mathrm{~mm}$ de diâmetro por $5 \mathrm{~mm}$ de comprimento para permitir o contato iônico com a solução de trabalho. Esse contato iônico se faz através das microtrincas que se formam no ato da solda da Pt ao vidro de borossilicato, devido à diferença nos coeficientes de dilatação de ambos materiais. Uma solução $3 \mathrm{~mol} \mathrm{~L}^{-1} \mathrm{KCl}$ foi colocada dentro desse tubo de vidro. Ambos os eletrodos foram adaptados às dimensões da célula $\mathrm{e}$ inseridos em orifícios de $3 \mathrm{~mm}$ de diâmetro localizados na borda da parte superior da célula e permitem o contato dos eletrodos com o eletrólito.

Como eletrodos de trabalho foram utilizados uma placa de aço comum laminada a frio (aço CFF) ${ }^{17}$ e o eletrodo de pasta de carbono (CPE) modificada com óxido de tungstênio.

Nos experimentos em que uma chapa de aço CFF de 18 por $18 \mathrm{~mm}$ foi utilizada como eletrodo de trabalho, após a preparação da superfície, a mesma foi ajustada sob o anel de vedação da parte superior da célula e fixada à parte inferior da mesma por meio de três parafusos.

Quando o eletrodo de trabalho era um eletrodo de pasta de carbono (CPE) foi necessário construir um suporte para a pasta. Esse suporte foi construído com um tarugo de grafite com $5 \mathrm{~mm}$ de altura e $6 \mathrm{~mm}$ de diâmetro da Alfa Æser (Graphite rod, 99\%,), embutido e centralizado 
em uma resina epóxi com 20 mm de diâmetro (Figura 1a (D)). Esse dispositivo se constituiu em suporte e contato elétrico para a pasta de carbono. Em seguida, a pasta de carbono foi fixada na superfície do tarugo de grafite. Então, a superfície da pasta foi modificada com o óxido de tungstênio que foi aderido sobre o CPE por pressão, uma vez que o pó de óxido de tungstênio não se fixa diretamente sobre a superfície do tarugo de grafite. Posteriormente, a parte inferior da célula contendo a pasta de carbono modificada foi ajustada sob o anel de vedação e fixada à parte superior da célula por meio dos três parafusos.
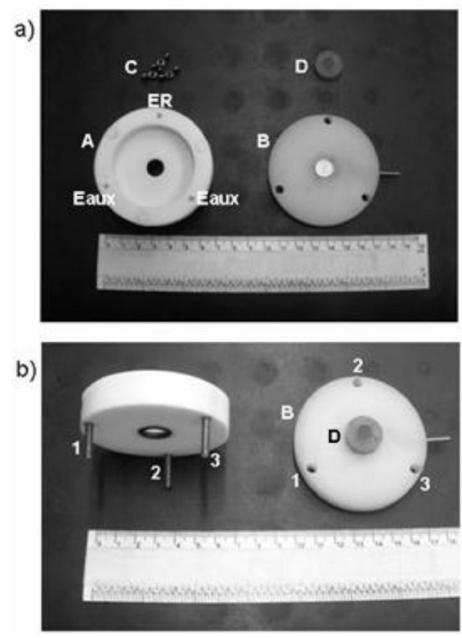

Figura 1. a) Imagem estendida da célula: (A) a parte superior da célula com três orifícios, ER e Eaux são os orifícios para os eletrodos de referência e auxiliares respectivamente; (B) a parte inferior da célula e ET o contato elétrico para o eletrodo de trabalho; (C) os parafusos, (D) o suporte de tarugo central e resina; b) imagem estendida da célula: (A) a parte superior da célula com três parafusos e (B) a parte inferior da célula e 1, 2 e 3 são os orifícios para os parafusos que unem as duas partes da célula

\section{Preparação dos eletrodos de trabalho}

Uma chapa de aço CFF foi cortada em amostras de $18 \times 18 \mathrm{~mm}$ e, em seguida, foi polida com lixas de carboneto de silício de granulometria 600 e 1200 . Em seguida, foi desengraxada com acetona em banho de ultrassom durante $5 \mathrm{~min}$. A amostra de aço assim preparada foi colocada sobre o contato elétrico da parte inferior da célula. Esta foi ajustada sob o anel de vedação por meio dos três parafusos.

O preparo do eletrodo de CPE-modificado foi realizado em duas etapas: o preparo da pasta de carbono e sua modificação. A pasta de carbono foi preparada conforme sugerido por Pereira e Kubota. ${ }^{18}$ Foram utilizados para a pasta: pó de tarugos de grafite da Alfa Æser 99,9\% com granulometria de 200 mesh e óleo mineral Fluka na proporção de 2:1 em massa, respectivamente. Em capela, $2 \mathrm{~mL}$ de clorofórmio foram adicionados à mistura que foi homogeneizada manualmente e após total evaporação do clorofórmio a pasta obtida foi empregada como eletrodo de trabalho.

Em seguida, a superfície da pasta de carbono foi modificada com óxido de tungstênio $\left(\mathrm{WO}_{3}\right)$ (Fluka 99,9\%) que foi aderido sobre o CPE por pressão mecânica (manual). Esse conjunto foi então colocado no orifício central localizado no fundo da primeira parte da célula eletroquímica (Figura 1a (A)), a qual foi fixada à segunda parte (Figura 1a (B)) pelos parafusos.

\section{Soluções de trabalho}

Nos ensaios com a chapa de aço CFF foram utilizados $18 \mathrm{~mL}$ de solução de $\mathrm{NaCl}$ 0,6 mol L-1 (3,5\%) e a corrosão do aço foi detectada com o auxílio da reação de complexação de íons $\mathrm{Fe}^{2+}$ com $2 \mathrm{~mL}$ de solução de 1,10- fenantrolina $0,05 \mathrm{~mol} \mathrm{~L}^{-1}$.

Para o estudo com o eletrodo de CPE-modificado foi utilizada uma solução de $\mathrm{Na}_{2} \mathrm{SO}_{4}, 0,2 \mathrm{~mol} \mathrm{~L}^{-1}$, pH 2. O pH da solução foi ajustado com ácido sulfúrico concentrado e medido com um peagômetro (medidor de $\mathrm{pH}$ ).

\section{Equipamentos}

Foi utilizado um bipotenciostato da Pine, modelo AFRDE 4, acoplado a um microscópio estereoscópio da Quimis, modelo Q734ZT acoplado a uma câmera digital colorida da Quimis, modelo SDC-312.

\section{DESEMPENHO DA CÉLULA ACOPLADA AO ESTEREOMICROSCÓPIO}

O teste inicial sobre o desempenho dessa célula foi feito com o eletrodo de aço CFF em solução de $\mathrm{NaCl}$ contendo 1,10-fenantrolina. A observação da amostra foi feita in situ e também foi possível obter fotografias da superfície do eletrodo mostrando as mudanças de coloração. A 1,10-fenantrolina é um dos melhores indicadores redox que existem, essa base combina-se facilmente, em solução, com sais de ferro na razão molar de 3 da base para 1 do íon ferro formando o complexo 1,10-fenantrolina-1́on ferro (II), de cor vermelha intensa na faixa de $\mathrm{pH}$ entre 2-9.19, 20

$$
\mathrm{Fe}^{2+}+3 \mathrm{C}_{12} \mathrm{H}_{8} \mathrm{~N}_{2} \rightarrow\left[\mathrm{Fe}\left(\mathrm{C}_{12} \mathrm{H}_{8} \mathrm{~N}_{2}\right)_{3}\right]^{2+}
$$

A aplicação de potenciais mais positivos que o potencial de circuito aberto $(-0,61 \mathrm{~V})$ gerou uma corrente crescente com o potencial (Figura 2) devido à reação de oxidação do $\mathrm{Fe}^{0}$ a $\mathrm{Fe}^{2+}$ e simultaneamente apareceu uma coloração vermelha característica da formação de complexo entre o cátion $\mathrm{Fe}^{2+}$ e a 1,10-fenantrolina.

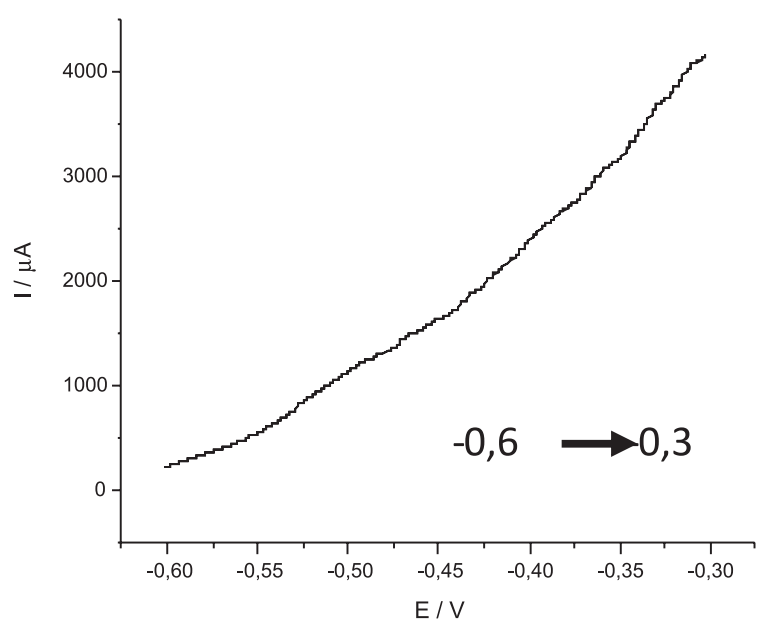

Figura 2. a) Curva corrente-potencial do aço CFF obtida em solução de $\mathrm{NaCl} 3,5 \%$ contendo 1-10 fenantrolina com varredura de potenciais entre $-0,6$ a $-0,3$ V a $5 \mathrm{mVs}^{-1}$

O aparecimento da cor vermelha foi nitidamente observado in situ, primeiramente sobre a superfície da peça de aço e posteriormente por toda solução devido à difusão dos íons $\mathrm{Fe}^{+2}$ (Figura 3).

Esse teste comprovou a eficiência da célula para a observação da superfície do eletrodo in situ. Assim, foram realizados ensaios com o eletrodo de CPE-modificado com óxido de tungstênio, visando observar também in situ mudanças no estado de oxidação ou outra modificação do óxido de tungstênio. 


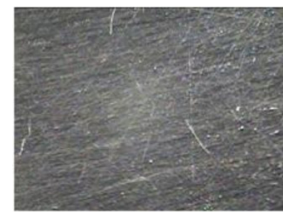

$E=-0,6 V$

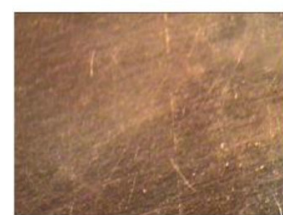

$E=-0,47 \mathrm{~V}$

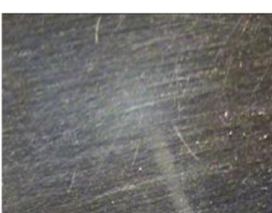

$E=-0,55 V$

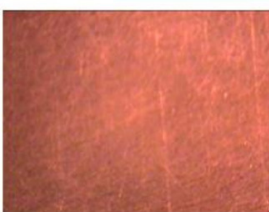

$\mathrm{E}=-0,43 \mathrm{~V}$

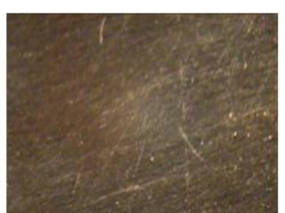

$E=-0,5 V$

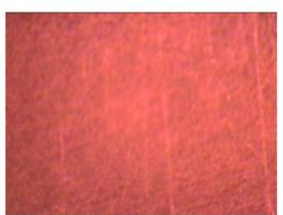

$E=-0,4 V$
Figura 3. Imagens da superfície do aço $\mathrm{CFF}$ em solução aquosa de $\mathrm{NaCl}$ $3,5 \%$ obtidas durante a varredura de potenciais a $5 \mathrm{mV} \mathrm{s} \mathrm{s}^{-1}$, registradas em diferentes potenciais

A Figura 4 mostra o voltamograma cíclico do CPE-modificado que foi obtido em $\mathrm{Na}_{2} \mathrm{SO}_{4}, 0,2 \mathrm{~mol} \mathrm{~L}^{-1}, \mathrm{pH}$ 2. Observa-se um aumento da corrente catódica a partir de $0,2 \mathrm{~V}$ com a presença de três picos de corrente ao redor de 0,$0 ;-0,25$ e $-0,75 \mathrm{~V}$, indicando pelo menos três processos distintos de redução desse óxido. Além disso, há um pequeno pico de corrente catódica, mal definido, ao redor de $-0,5 \mathrm{~V}$. Invertendo-se o sentido da varredura de potencial observam-se três picos discretos de corrente anódica ao redor de $-0,8 ;-0,3$ e $+0,25 \mathrm{~V}$, que poderiam estar associados aos picos de corrente catódica observados na varredura direta. Os números de 1 a 15 do voltamograma cíclico indicam os potenciais onde foram registradas as micrografias das Figuras 5 e 6.

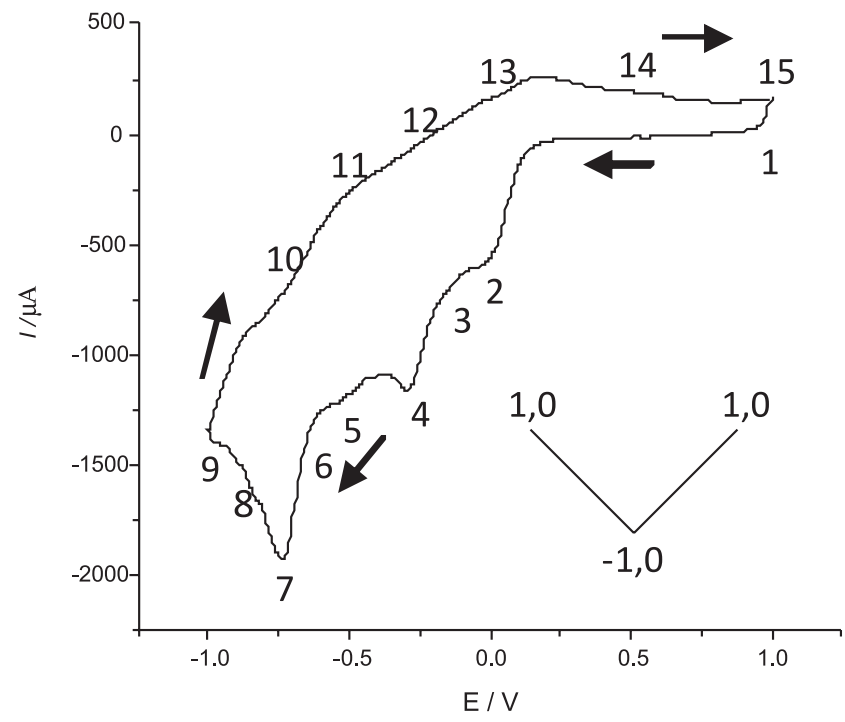

Figura 4. Voltamograma cíclico da pasta de grafite modificada com $\mathrm{WO}_{3}$, em $\mathrm{Na}_{2} \mathrm{SO}_{4}$ 0,2 $\mathrm{mol} \mathrm{L}^{-1}$, pH 2 e v $=5 \mathrm{mV} \mathrm{s}^{-1}$. Os números de 1-15 indicados no voltamograma cíclico correspondem aos potenciais onde foram obtidas as micrografias da Figura 6

A Figura 5 mostra as fotografias da superfície do eletrodo de trabalho obtidas durante a varredura de potencial. Observase o processo de redução da amostra com a mudança de cor da superfície do eletrodo de óxido, que passa de amarelo para azul escuro (Figura 5). O início dessa mudança ocorre em potenciais entre $-0,1$ e $-0,2 \mathrm{~V}$.

O processo de mudança de coloração mostra-se reversível, pois quando a varredura é efetuada no sentido de potenciais positivos observa-se novamente a coloração inicial (Figura 6), que é atribuída à oxidação do tungstênio. O processo eletroquímico não segue pro-

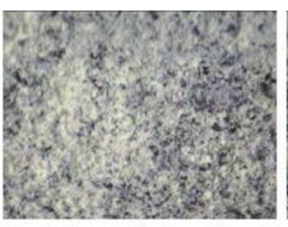

$E=1,0 \vee$

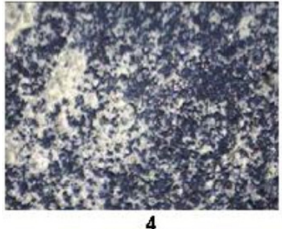

$E=-0,25 V$

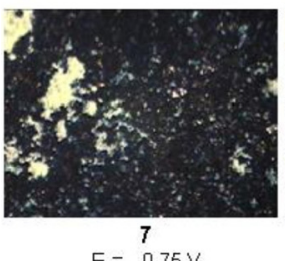

$\mathrm{E}=-0.75 \mathrm{~V}$

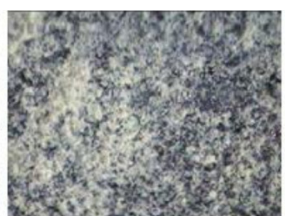

2
$E=0.0$

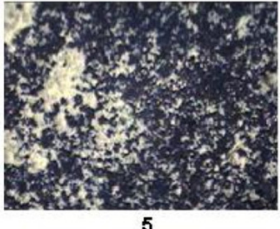

$E=-0,5 \mathrm{~V}$

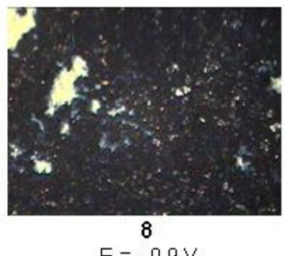

$E=-0,9 \mathrm{~V}$
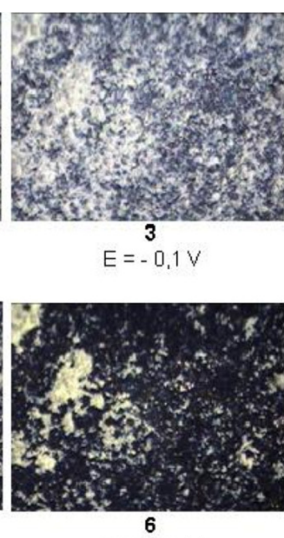

$E=-0.6 V$

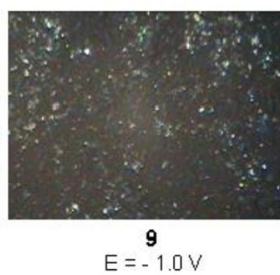

Figura 5. Imagens da superfície do eletrodo de trabalho modificado com WO gravadas pela câmera acoplada ao estereomicroscópio durante a varredura de $1,0 \rightarrow-1,0 \mathrm{~V}$, indicando os potenciais em que foram registradas as micrografias
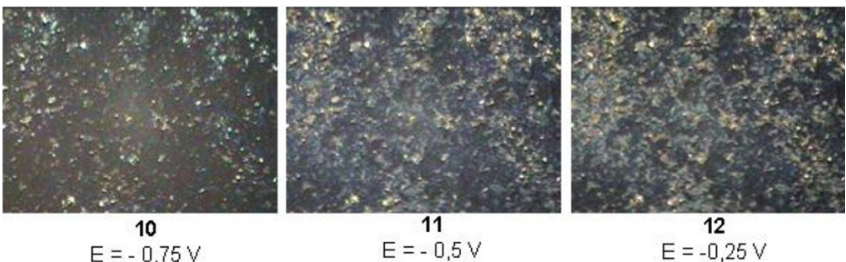

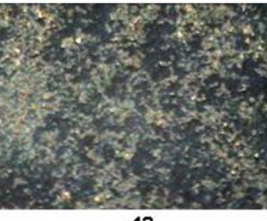

$E=0,0 \mathrm{~V}$

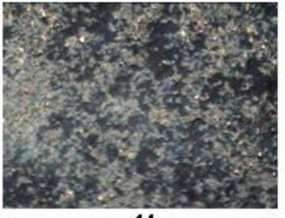

$=+0.5 V$

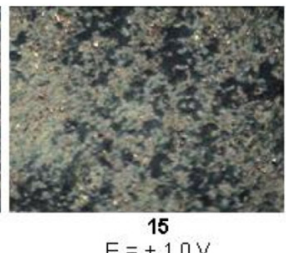

Figura 6. Imagens da superfície do eletrodo de trabalho modificado com $W_{3}$ gravadas pela câmera acoplada ao estereomicroscópio durante a varredura $-0,75$ a 1,0 $\mathrm{V}$, indicando os potenciais em que foram registradas as micrografias (ver Figura 5)

priamente o comportamento previsto pela Equação de Nernst, porém, o estado de oxidação é recuperado em potenciais mais positivos, onde se observa a mudança de coloração para a cor original.

Esse fenômeno de mudança de coloração e os picos de corrente catódica observados durante a varredura de potenciais estão associados ao fenômeno eletrocrômico apresentado pelo $\mathrm{WO}_{3}$.

As reações eletrocrômicas do $\mathrm{WO}_{3}$ têm sido descritas por vários modelos, ${ }^{21-25}$ mas o mais amplamente aceito é o modelo da dupla injeção, ${ }^{21} \mathrm{o}$ qual assume que o processo de coloração é devido à inserção de íons monovalentes na matriz de acordo com a reação 2):

$$
\mathrm{WO}_{3}+\mathrm{xM}^{+}+\mathrm{xe}^{-} \rightleftarrows \mathrm{M}_{\mathrm{x}} \mathrm{WO}_{3}
$$

Para garantir a eletroneutralidade do meio, a inserção de um íon, em geral um cátion monovalente $\mathrm{M}^{+}$, dentro da rede do composto, deve ser acompanhada pela injeção de um elétron, balanceando as cargas na rede cristalina do óxido de tungstênio de acordo com a 
Equação 2. Neste trabalho, devido à utilização de eletrólito aquoso com $\mathrm{pH}$ 2, o processo eletrocrômico é devido à inserção reversível de prótons $\mathrm{H}^{+}$, dentro da rede do $\mathrm{WO}_{3}$.

Dessa forma, as mudanças de cor foram interpretadas com base na diminuição de espécies de tungstênio ( $\left.\mathrm{W}^{\mathrm{VI}}\right)$ que, por redução, são convertidas em espécies de tungstênio $\mathrm{W}^{\mathrm{V}}$ na rede, com simultânea inserção de prótons em meio aquoso. Esse processo se traduz no aumento do número de centros de cor. Estudos recentes de espectroscopia de fotoelétrons induzida por raios X (XPS) demonstraram que durante o processo eletroquímico de redução do óxido realmente aumenta o sinal atribuído ao $\mathrm{W}^{\mathrm{V}}$ (trabalho não publicado).

\section{CONCLUSÕES}

A célula eletroquímica proposta é de fácil confecção, baixo custo e possibilita seu acoplamento a um estereomicroscópio para registro de imagens. Esse acoplamento permite a observação in situ e, no caso dos materiais eletrocrômicos, permite observar a mudança de cor referente ao fenômeno eletrocrômico, apresentando voltamogramas de boa resolução, similares aos obtidos em célula eletroquímica convencional.

Essa célula adaptada é versátil e não se restringe ao estudo dos materiais eletrocrômicos podendo também ser utilizada em estudos de corrosão, observação de fases e defeitos em revestimentos, eletrodepósitos, formação de precipitados etc. Pode também ser empregada em experimentos envolvendo medidas em circuito aberto e todas as técnicas eletroquímicas empregando eletrodos sólidos, CPEs-modificados e uma série de outras possíveis aplicações em eletroquímica.

\section{MATERIAL SUPLEMENTAR}

Está disponível em http://quimicanova.sbq.org.br, na forma de arquivo. PDF, com acesso livre. A Figura 1S mostra a célula eletroquímica completa, montada e acoplada ao estereomicroscópio.

\section{AGRADECIMENTOS}

Às agências de fomento CNPq e CAPES pelas bolsas e auxílios concedidos.

\section{REFERÊNCIAS}

1. Lampert, C. M.; Grandqvist, C. G.; Large-Área Chromogenics: Materials and Devices for Transmittance Control; SPIE IS4, Bellingham: Washington, 1990.

2. Oliveira de, S. C.; Torresi, R. M.; Torresi, S. I. C.; Quim. Nova 2000, 23, 79.

3. Randin, J. P.; Eletronics 1981, 29, 89.

4. Lynam, N. R.; SAE Int. Congress and Exhibition, February 23-27, 1987, Paper 870636.

5. Kase, T.; Kawai, M.; Ura, M.; SAE Passenger Car Meeting and Exposition, September 22 - 25, 1986, Paper 861362.

6. Lampert, C. M.; Sol. Ener. Mater. 1982, $2,1$.

7. Svensson, J. S. E. M.; Grandqvist, C. G.; Proc. SPIE 1984, 502, 30.

8. Granqvist, C. G.; Sol. Ener. Mater. 2008, 92, 203.

9. Karuppasamy, A.; Subrahmanyam, A.; Thin Solid Films 2007, 516, 175.

10. Yao, J. N.; Chen, P.; Fujishima, A.; J. Eletroanal. Chem. 1996, 406, 223.

11. Fei, J.; Lim, K. G.; Tayhas, G.; Palmore, R.; Chem. Mater. 2008, 20 , 3832.

12. Udum, Y. A.; Durmus, A.; Gorkem, E.; Toppare, G. L.; Org. Electron. 2008, $9,501$.

13. Hsu, C. S.; Chan, C. C.; Huang, H. T.; Peng, C. H.; Hsu, W. C.; Thin Solid Films 2008, 516, 4839.

14. Rougier, A.; Sauvet, K.; Sauques, L.; Ionics 2008, 14, 99.

15. Kim, J. J.; Tryk, D. A.; Amemiya, T.; Hashimoto, K.; Fujishima, A.; J. Eletroanal. Chem. 1997, 435, 31.

16. Smulko, J.; Azens, A.; Kish, L. B.; Granqvist, C. G.; Smart Mater. Struct. 2008, 17, 025005.

17. Modiano, S.; Fugivara, C. S.; Benedetti, A. V.; Corros. Sci. 2004, 46, 529.

18. Pereira, A. C.; Kubota, L. T.; Quim. Nova 2004, 27, 725.

19. Morita, T.; Assumpção, R. M. V.; Manual de soluções, reagentes e solventes, $2^{\mathrm{a}}$ ed., Blucher: São Paulo, 2007.

20. Furman, N. H.; Standard Methods of Chemical Analysis, $6^{\text {th }}$ ed., D. van Nostrard Company: New Jersey, 1961.

21. Torresi, S. I. C.; Gorenstein, A.; Torresi, R. M.; Vázquez, M. V.; J. Electroanal. Chem. 1991, 318, 131.

22. Déb, S. K.; Sol. Energy Mater. Sol. Cells 2008, 92, 245.

23. Bathe, S. R.; Patil, P. S. J.; Appl. Phys. 2007, 40, 7423.

24. Sivakumar, R.; Gopalakrishnan, R.; Jayachandran, M.; Sanjeeviraja, C.; Smart Mater. Struct. 2006, 15, 877.

25. Oliveira, S. C.; Torresi, R. M.; Torresi, S. I. C.; Quim. Nova 2000, 23, 79. 


\section{CONSTRUÇÃO DE CÉLULA ELETROQUíMICA PARA OBSERVAÇÃO DE AMOSTRAS IN SITU EM ESTEREOMICROSCÓPIO}

Mônica Alessandra Silva Alencar *, Assis Vicente Benedetti, Cecílio Sadao Fugivara e Younès Messaddeq Instituto de Química, Universidade Estadual Paulista, CP 355, 14801-970 Araraquara-SP, Brasil

\section{MATERIAL SUPLEMENTAR}

A Figura 1S mostra a célula eletroquímica completa, montada e acoplada ao estereomicroscópio.

a)

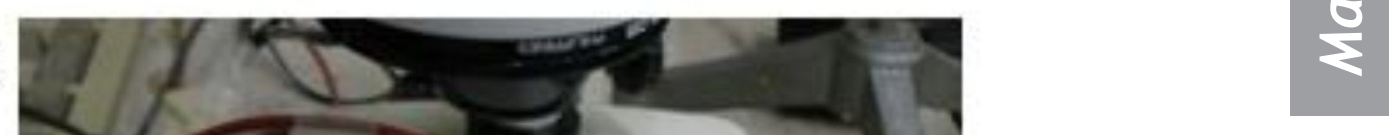

b)

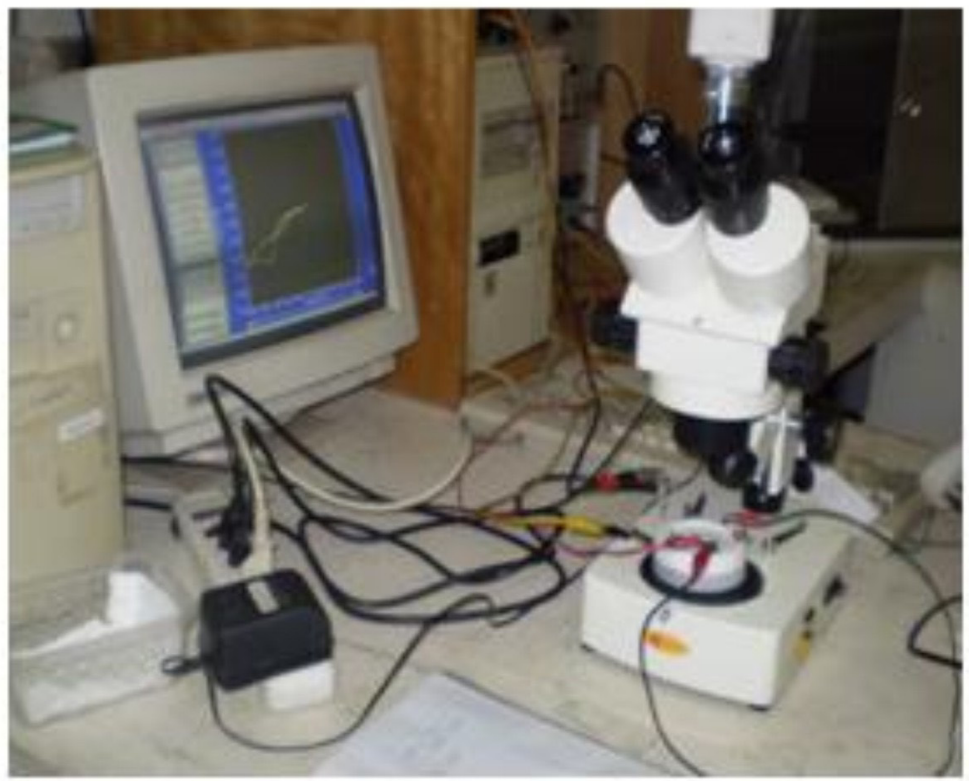

Figura 1S. a) Imagens da célula eletroquímica montada sendo observados os respectivos eletrodos utilizados, b) a célula eletroquímica ligada ao bipotenciostato da PINE e acoplada a um estereomicroscópio 